\title{
Microcompression of brittle and anisotropic crystals: recent advances and current challenges in studying plasticity in hard materials
}

\author{
Sandra Korte-Kerzel, Institute of Physical Metallurgy and Metal Physics, RWTH Aachen University, Kopernikusstraße 14, 52074 Aachen, Germany \\ Address all correspondence to S. Korte-Kerzel at korte-kerzel@imm.rwth-aachen.de
}

(Received 22 January 2017; accepted 7 March 2017)

\begin{abstract}
Recent years have seen an increased application of small-scale uniaxial testing — microcompression—to the study of plasticity in macroscopically brittle materials. By suppressing fast fracture, new insights into deformation mechanisms of more complex crystals have become available, which had previously been out of reach of experiments. Structurally complex intermetallics, metallic compounds, or oxides are commonly brittle, but in some cases extraordinary, though currently mostly unpredictable, mechanical properties are found. This paper aims to give a survey of current advances, outstanding challenges, and practical considerations in testing such hard, brittle, and anisotropic crystals.
\end{abstract}

While the origin of mechanical strength, toughness, and creep resistance is well studied in most metals, much less is known about the properties of more complex crystal structuresdespite their wide use as reinforcement phases and the undiscovered potential in their sheer number and variability. A major challenge in plasticity research of the next years will therefore be to close this gap in knowledge. Small-scale testing techniques have been demonstrated as a key enabling technique for such studies. Most prominent is microcompression, which helps overcome the fundamental challenge of studying plasticity in materials, which suffer from extreme brittleness in conventional testing. ${ }^{[1,2]}$ Their plastic properties may, at first glance, appear to be of only academic interest: aiming to deduce fundamental relationships of crystal plasticity and structure to enable knowledge-guided search and data mining for new structural materials. However, they are in fact essential to performance at the microstructural scale of many advanced and highly alloyed materials and to understanding the effects of alloying strategies aimed at inducing deformability as baseline or reference information.

\section{Investigating plasticity in hard crystals}

A deep understanding of plasticity and dislocation motion exists in most metallic crystals and strategies to engineer different aspects, for example by adjustment of the stacking fault energy, have been very successful. ${ }^{[3,4]}$ These are being applied - with great effect - to hexagonal metals ${ }^{[3]}$ which in spite of their closely related atomic packing show strongly anisotropic deformation and are therefore much more difficult to deform at low temperatures. In BCC metals, fundamental aspects of dislocation core structure, stress tensor dependence, and resulting non-Schmid behavior, are also still under investigation. ${ }^{[5,6]}$ However, in all of these materials, the availability of large-grained or single crystals with sufficient purity has scarcely been a problem, nor has the ability to deform such samples under carefully controlled conditions. Suitable investigations by conventional, analytical and high-resolution microscopy techniques have also been carried out whenever new methods have allowed researchers to dive deeper into the physics of their plastic deformation.

In intermetallics, ceramics, and compounds we face challenges at a far more fundamental level. In addition to the overwhelming number and variability of these crystals, even where only binary and ternary systems are considered as a starting point, it is the simple step at the beginning of the research process, which has proved a major obstacle: achieving basic samples deformed under known and carefully controlled reference conditions for further analysis.

Specific challenges in studying such brittle and/or anisotropic crystals therefore lie in:

- Avoiding premature fracture during deformation at temperatures below the macroscopic brittle-to-ductile transition temperature.

- Achieving uniaxial stress states to target individual slip systems and extract critical resolved shear stresses.

- Assuring that the same mechanical test methods are applicable for a direct comparison within any set of investigated alloys or crystal structures, including both the ductile and brittle variants.

- Resolving the local (mobile) defect structure, even where the above aspects have been satisfied, for high-resolution 
characterization in crystals with large unit cells, containing both very light and heavy elements and without pre-conceived insights into the possible dislocation core structures, often including several partials, to guide the experiment.

- Modeling of the structure, or more complex yet the motion, of dislocations in crystals with large unit cells and containing several atomic species, including those in which magnetism might have to be considered in atomic scale modeling.

Research in hard materials traditionally uses indentation at all scales and compression under triaxial stresses, providing a confining element to make the opening of a crack resulting in fracture energetically less favorable. ${ }^{[7,8]}$ Alternatively, tests are conducted at high temperatures to achieve plastic deformation by the motion of dislocations at stresses below those required to extend a crack. The most extreme cases of these types of experiments may be found in the geological sciences, where mantle materials are investigated at several times atmospheric pressure. ${ }^{[9]}$

In engineering materials, hard crystals are employed to carry loads in four predominant classes of materials: the very hard ceramic or intermetallic bulk parts used nearly exclusively in compression to avoid catastrophic failure from intrinsic flaws, hard coatings giving wear protection in application or tooling, and composites of hard phases with softer matrices aiming at a beneficial combination of the properties of both materials. Finally, hard phases, in particular intermetallics and carbides, are found as intentional or undesired precipitates within a metallic matrix (Fig. 1).

Where these are very small and densely spaced, they may act as obstacles to dislocations, one of the major hardening mechanism employed in metals. ${ }^{[10]}$ In these cases, the intrinsic strength is not of primary importance as size and crystal relationship with the matrix determine the efficiency as obstacles to dislocations. In highly alloyed systems, such as superalloys used in turbines, the use of a large collection of elements results in the formation of a number of stable phases as precipitates, often as carbides or topologically close-packed phases containing several refractory elements ${ }^{[11]}$ [Fig. 1(b)]. While their structures and crystal relationships with the surrounding matrix is well studied, qualitative data with respect to the operative slip systems and quantitative data on the respective stresses are largely missing. ${ }^{[12]}$ Where defect structures have been studied in the related bulk phases, these are often growth defects due to the difficulties encountered in producing large single crystals and deforming them at relevant application temperatures, i.e., high temperatures near $1000{ }^{\circ} \mathrm{C}$ during power conversion and near room temperature during ramp up/down where the risk of fracture increases. ${ }^{[13-15]}$ Quantitative measurements of hardness circumvent the problem of specimen size by testing at the nanometer scale directly within precipitates; however, this technique is still largely limited to room temperature in most laboratories and anisotropy of a crystal is usually difficult to considered with explicit reference to individual slip planes in such studies. ${ }^{[16]}$

\section{Microcompression: a new way to study plasticity in hard crystals}

The majority of challenges in studying plasticity in brittle materials have been overcome recently by means of small-scale
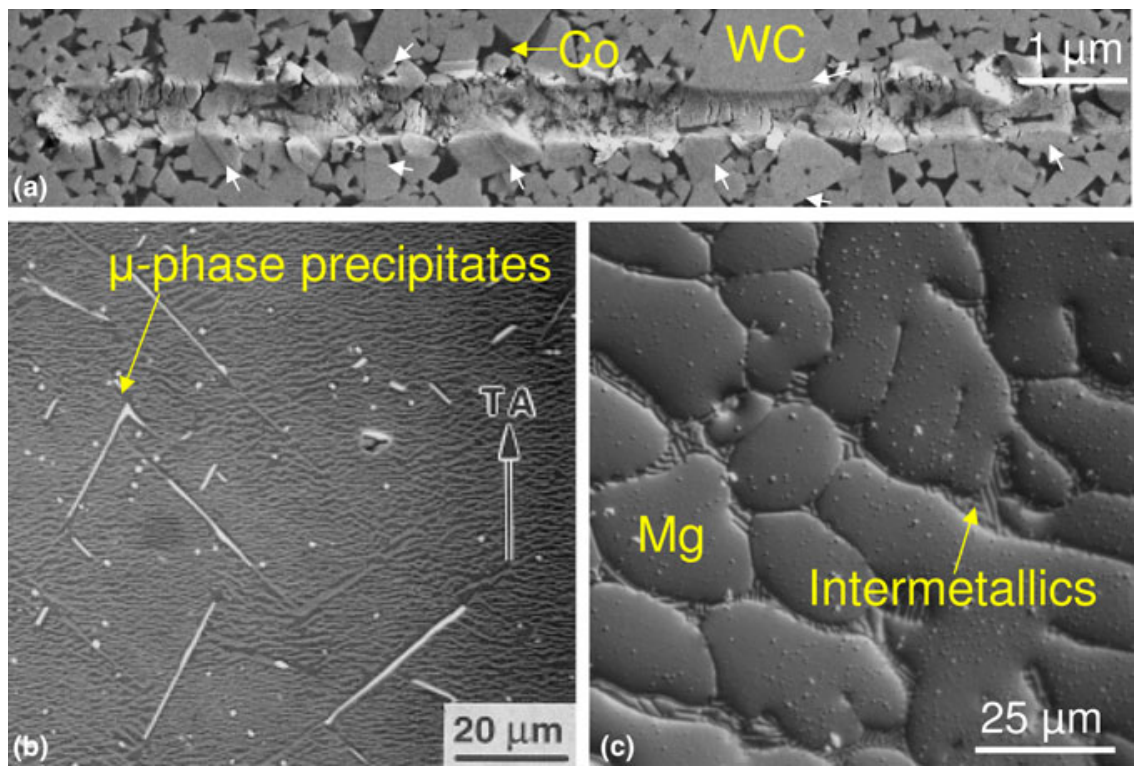

Figure 1. Examples of hard phases in engineering materials. (a) Tungsten carbide in the cemented carbide WC-Co exhibiting plastic deformation in nanoscratch testing, (b) topologically close-packed $\mu$-phase precipitates in a nickel-based superalloy after creep-testing and (c) intermetallic skeleton included in cast Mg-AlCa alloy to increase creep resistance. [images: (a) courtesy of J. S. K.-L. Gibson; (b) Reprinted with permission from Elsevier Ref. 86; (c) courtesy of C. Zehnder] 
testing, in particular microcompression, which has allowed the characterization of plasticity under previously inaccessible conditions. First demonstrated in $2004,{ }^{[17]}$ it was initially used predominately to investigate the effect of size on strength in metals previously confined to whiskers. ${ }^{[18-20]}$ However, this method soon proved exceedingly useful in the study of brittle materials by addressing the challenges outlined above, particularly the fundamental possibility to avoid brittle fracture by scaling down the size of the experiment.

Research of the last few years was focused on adapting the "microcompression" technique to characterize hard and brittle materials at small scales without fracture and while distinguishing anisotropic plastic properties. ${ }^{[2,21-32]} \mathrm{A}$ selection of materials thus studied in terms of their plasticity is shown in Fig. 2, while Figs. 3-6, 8, and 10 also contain examples of materials, which are shown to deform plastically well below their macroscopic brittle-to-ductile transition temperature. For an example, Fig. 3 presents the first study of silicon at low, but variable temperatures without a hydrostatic pressure component allowing analysis of the active slip systems and supporting the theoretical hypothesis of a change in slip system with temperature. ${ }^{[31,33]}$ The conventional scheme for studies of directional plasticity in brittle crystals using microcompression on a polycrystalline sample in correlation with electron backscatter diffraction (EBSD) and where desired transmission electron microscopy (TEM) is shown in Fig. $4 .^{[34]}$

Only a few years after its first use, the microcompression technique was made even more powerful in unraveling deformation mechanisms by enabling experiments at elevated temperatures. ${ }^{[35,36]}$ In nanoindentation, the related nanomechanical method based on the same equipment, publications are currently rising every year with respect to the development of high-temperature capability and the limit is being pushed toward $1000{ }^{\circ} \mathrm{C}$, reaching application temperatures of turbine materials. ${ }^{[37,38]}$ In addition, variable rate experiments ${ }^{[39]}$ now allow the characterization of rate dependence from the impact $^{[40]}$ to the creep regime ${ }^{[41,42]}$ at any given temperature. These experiments now allow the study of temperaturedependent effects in dislocation plasticity, such as the change in the resistance of the lattice to dislocation motion or transitions in dislocation structure. In conjunction with in- and ex-situ microscopy techniques, ${ }^{[25,43]}$ microcompression is therefore ideally suited to reveal the plasticity mechanisms and any anisotropy of brittle materials, which cannot be studied otherwise at low temperatures. This also includes their ductile counterparts, which might be available only in small volumes such as thin films or microscopic precipitates.

Among the systems, which have been studied to date by research groups around the globe are $\mathrm{Cu}-\mathrm{Sn}$ phases (solders), carbides and nitrides, MAX phases, binary nickel and iron aluminides, metallic and silicate glasses, high entropy alloys and quasicrystals, ${ }^{[2,21-32,36,44-48]}$ see also Fig. 2. This rapid integration of the technique to the repertoire of research in hard materials highlights its usefulness in analyzing plasticity in hard materials.

\section{Specific aspects of microcompression}

In the following, those aspects most important to studies of plasticity in hard, brittle, and anisotropic materials are highlighted and discussed both in terms of their often unique advantages and associated challenges still to be overcome. Reviews and analyses of experimental difficulties, potential artifacts, and also size effects in microcompression or related nanoindentation methods in general are numerous in the literature $^{[18,38,39,49-55]}$ and therefore only those aspects directly relevant to hard, brittle, and/or anisotropic crystals are considered here.

\section{Suppressing fracture in microcompression}

The effect of size on fracture has long been known in particle technology as the grinding limit, where further breakdown of particles ceases, ${ }^{[56]}$ and has been at the heart of most established theories of fracture where critical flaw sizes of ratios between surface area created and volume elastically relaxed are considered. ${ }^{[57]}$ It is the scaling laws in these concepts and the small volume, excluding pre-existing cracks, which allow the plastic deformation of even the most brittle materials by microcompression.

It was shown that where no pre-existing cracks are present, it is their nucleation - as a result of dislocation motion, intersection and lock formation - which must be avoided to achieve significant plasticity. ${ }^{[2]}$ This is illustrated in Fig. 5 and of course depends on both the crystal orientation allowing single or multiple slip, as well as the relative stresses at which dislocations move or cracks extend, once nucleated. Within Fig. 3 the approach shown in Fig. 5 is applied in terms of the temperaturedependent flow stress and size of silicon micropillars and shows very good correlation of the experimentally observed and predicted ductile and brittle regimes. Other mechanisms and geometries of cracking have also been discussed in the literature $^{[1,23]}$ and a size effect on the deformation behavior is also observed in the amorphous bulk metallic glasses, although its physical origin and magnitude is still under debate. ${ }^{[58]}$

\section{Characterization of individual slip systems in hard and anisotropic materials}

In hexagonal, ionic, and/or ordered structures, but especially in anisotropic crystals of which a substantial fraction has larger unit cells, it is important to be able to distinguish the properties of individual slip systems. Indentation is largely representative of the resistance governing three-dimensional (3D) accommodation of the tip, i.e., often the hardest slip system that is required to operate to fulfill the von Mises criterion. In contrast, failure - or in fact machinability as more desirable quality in brittle materials - is commonly governed by the weakest link, that is the softest slip system. A prominent example of this is given by the MAX phases, ${ }^{[59]}$ atomically layered ternary carbides with a critical resolved shear stress on the basal planes that is much lower than the commonly factor of the order of six assumed to link critical or flow shear stresses and hardness. 


\section{Carbides \& Borides}
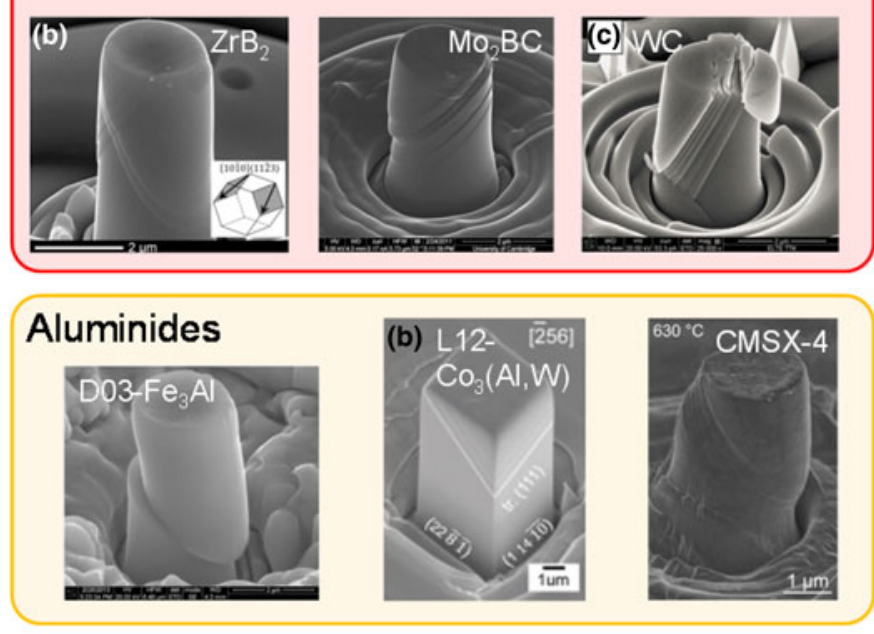

\section{Semiconductors}

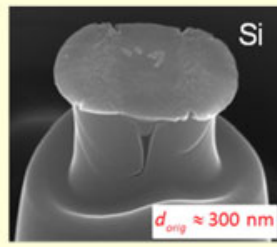

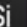
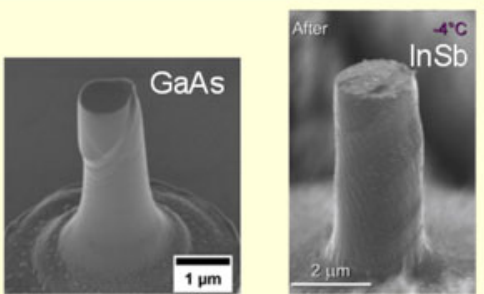

\section{Oxides}
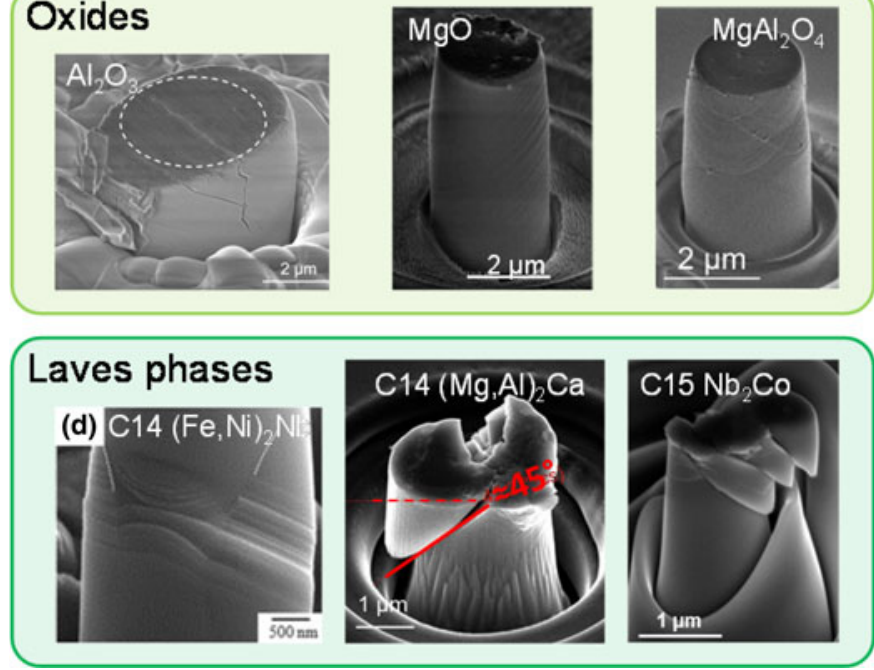
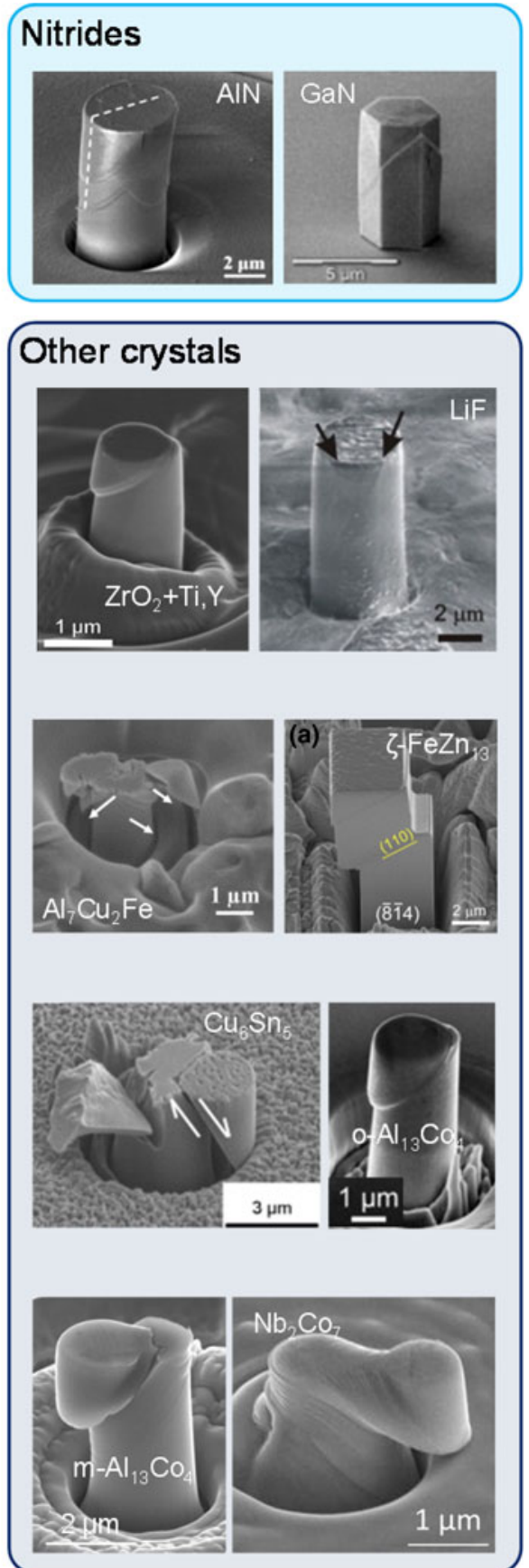

Figure 2. Selection of hard crystals tested by microcompression. $\mathrm{ZrB}_{2},{ }^{[87]} \mathrm{Mo}_{2} \mathrm{BC},{ }^{[85]} \mathrm{WC}^{\left[{ }^{[21]}\right.} \mathrm{Fe}_{3} \mathrm{Al},{ }^{[88]} \mathrm{Co}_{3}(\mathrm{Al}, \mathrm{W}),{ }^{[89]} \mathrm{CMSX}-4,{ }^{[36]} \mathrm{Si},{ }^{[31]} \mathrm{GaAs},{ }^{[2]} \mathrm{InSb},{ }^{\left[{ }^{[90]}\right.}$

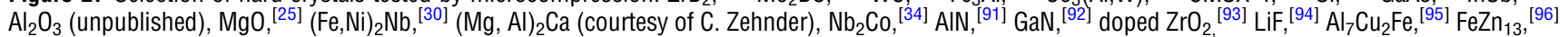
$\mathrm{Cu}_{6} \mathrm{Sn}_{5},{ }^{[24]} \mathrm{m}-\mathrm{Al}_{13} \mathrm{CO}_{4}$ (unpublished), $0-\mathrm{Al}_{13} \mathrm{Co}_{4},{ }^{[44]} \mathrm{Nb}_{2} \mathrm{Co}_{7} \cdot{ }^{[34]}$ Reprinted with permissions by Elsevier, Cambridge University Press and Taylor \& Francis Ltd. (www.tandfonline.com) from the references given for each material.

In microcompression, a near uniaxial stress state can be achieved and specific orientations for the single-crystal constituting the sample may be chosen and characterized individually (see Fig. 6); either by producing a well aligned single crystal and preparing several identical pillars by employing focused ion beam (FIB) milling or lithography, or alternatively by using EBSD to map the local crystal orientation followed by the site-specific FIB preparation. If the slip systems which operate in a given crystal structure are not known a priori, then indentation may nevertheless be exceedingly useful in a purposeful preparation of the more involved microcompression experiments. Correlated EBSD-nanoindentation maps may be used to identify statistically those slip planes on which deformation occurs if slip traces are formed on the surface. TEM, 


\section{Suppression of cracking $\Rightarrow$ Testing at low temperatures $\Rightarrow$ Dislocation analysis}
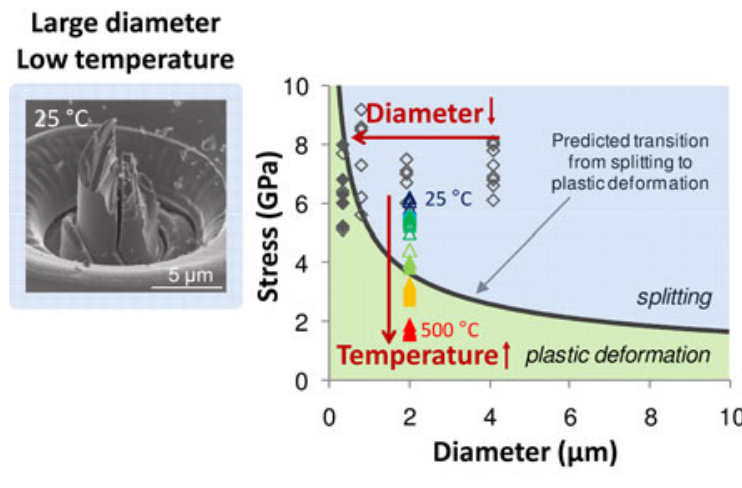

\section{Small diameter \\ High temperature}
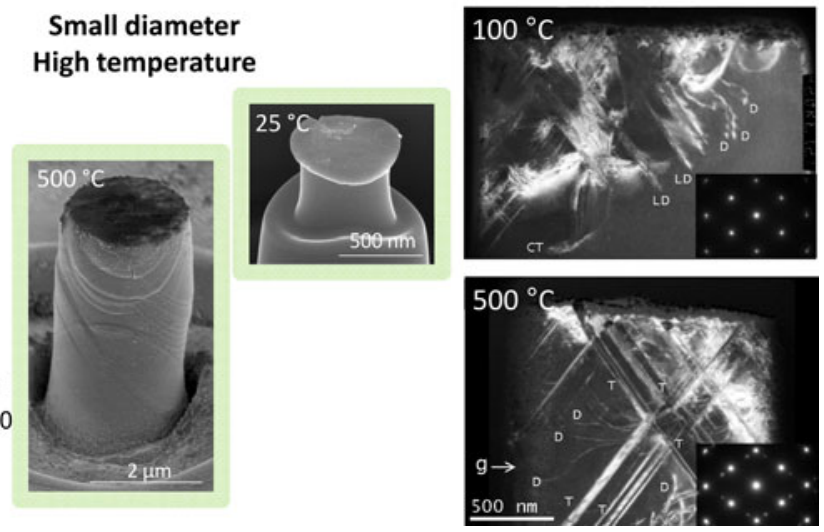

Figure 3. Use of microcompression testing to characterize flow in brittle materials in previously mostly inaccessible low-temperature regime (here silicon). The reduction in size allows suppression of fast fracture with cracks forming at slip band intersections [locked dislocations (LD) in TEM micrograph, top right] and propagating axially [scanning electron microscopy (SEM) micrograph at far left], while testing over a range of temperature allows the study of thermally activated flow and analysis of dislocation structures by electron microscopy. Reprinted with permission by Elsevier from Ref. 31.

either conventional or high resolution, is easily performed after compression by the site-specific FIB milling and where necessary further thinning of a transparent membrane from the micropillar (see Figs. 3, 4, 6, and 10, for examples).

\section{Size effects in hard crystal: dislocation motion and nucleation}

The stresses measured are affected by size effects on plasticity. ${ }^{[19,53]}$ Here, an advantage lies in a high bulk intrinsic strength governed by the lattice resistance due to the intrinsically much smaller length scale of double kink formation. Similarly, materials already strengthened by exploiting a length scale significantly below the pillar size, e.g., in dispersion and precipitation strengthened alloys, ${ }^{[17,60]}$ exhibit a smaller or negligible size effect within the range of sizes studied by microcompression. This is shown for a range of materials in Fig. 7, including a fit using one of the simplest expressions for size effects due to source size as given by Parthasarathy et al. ${ }^{[61]}$

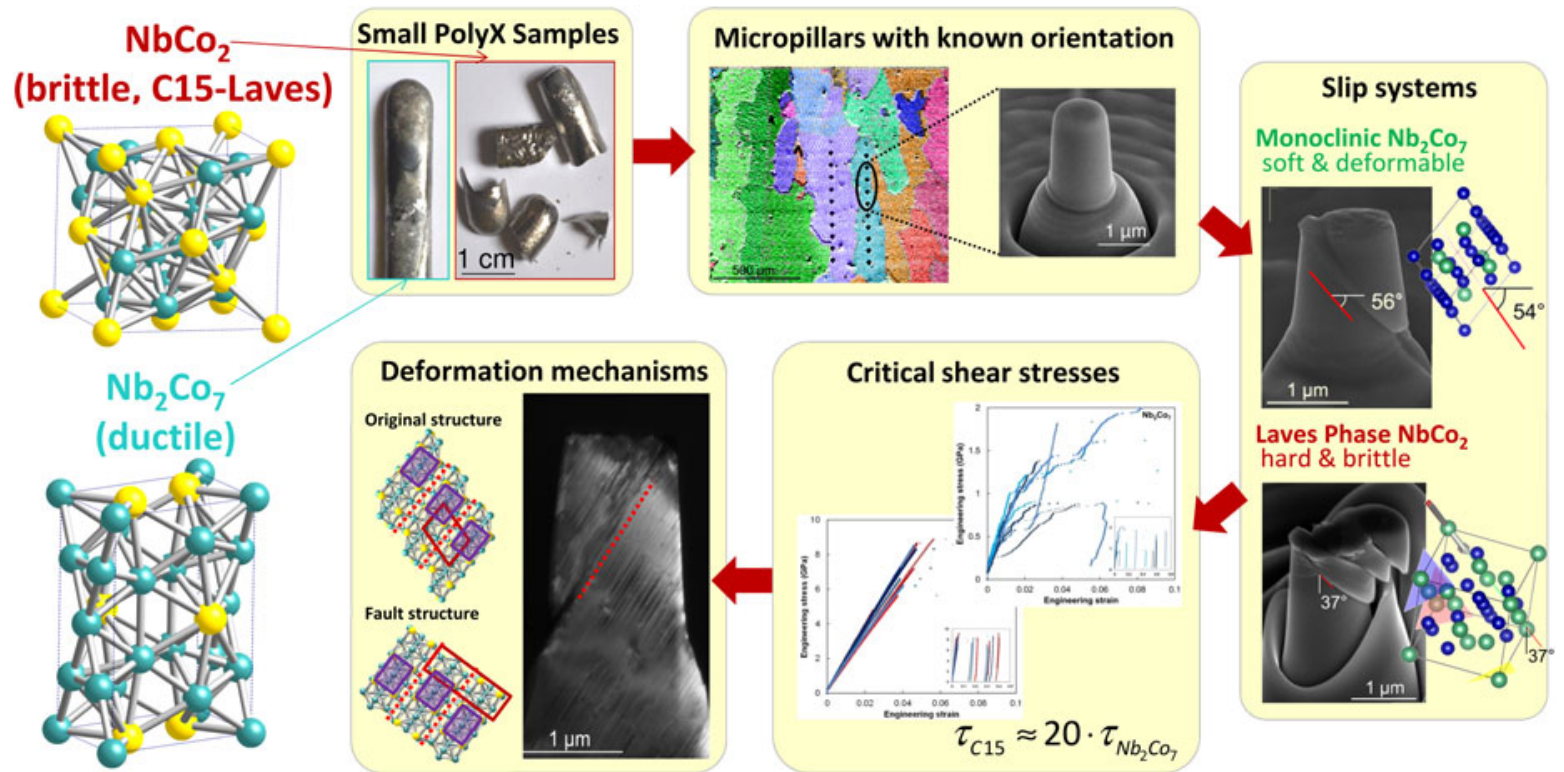

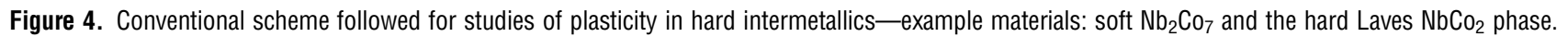
Following sample preparation by arc-melting, micropillars are machined by focused ion beam milling in grains with known orientation and slip planes analyzed after compression, where the reduction in size leads to suppression of cracking. As a result, critical shear stresses can be measured and mechanically induced defects investigated. Parts of this figure are reprinted with permission by John Wiley \& Sons from Ref. 34. 

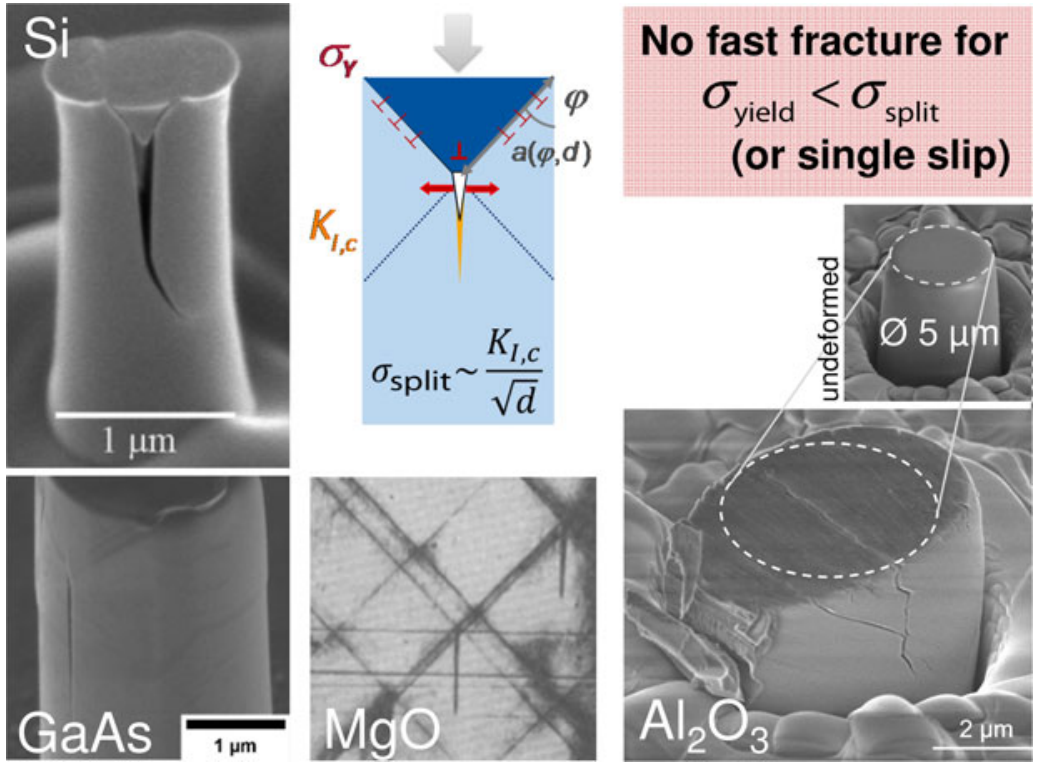

Figure 5. Axial splitting and suppression of fast fracture in semiconductors and oxide ceramics. Splitting model/geometry from Ref. 2 Reprinted with permission by Taylor \& Francis Ltd. (www.tandfonline.com) from Ref. 2, John Wiley and Sons from Ref. 1 and Springer from Ref. 97, ( $\mathrm{Al}_{2} \mathrm{O}_{3}$ : unpublished).

The higher intrinsic strength therefore reduces the factor by which small-scale characterization overestimates the bulk material strength, producing more directly applicable data. This is also shown in a direct comparison of the critical resolved shear stress of $\mathrm{MgO}$ on the soft and hard slip systems with macroscopic data in Fig. 6, where a much more pronounced deviation is found on the soft system for identical processing and testing conditions.

The hard materials are also often less prone to FIB damage in the form of formation of dislocations as seen frequently in the soft metals. ${ }^{[52]}$ Only a blessing at first glance, this does mean that nucleation must be considered to play a substantial role in determining the stresses required for deformation. In metals, where the stress required to move a dislocation, even a short segment, is usually much lower than the nucleation stress, the regimes of dislocation motion and nucleation are often readily distinguished. ${ }^{[62]}$ In very hard materials, the critical stresses for dislocation nucleation (i.e., a fraction of the shear modulus), and the stress to overcome the lattice resistance may be close enough to not allow a distinction based on stress level alone. This is due to the experimental scatter and uncertainties of the stress calculation, such as the choice of representative cross-sectional area in tapered micropillars. As a result of the similar activation volumes of double kink formation and
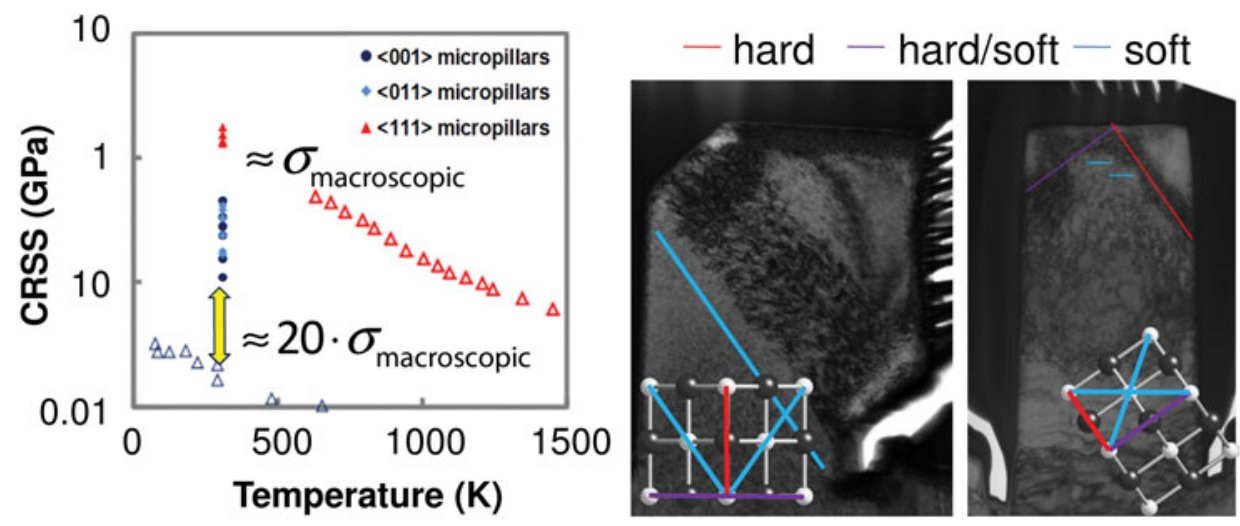

Figure 6. Characterization of individual slip systems in highly anisotropic crystals, here Mg0. By choice of crystal orientation, like in macroscopic single-crystal studies, slip on specific sets of systems can be activated, analyzed by TEM and quantitative measurements of the critical resolved shear stresses achieved. A comparison of the soft $\{110\} \frac{1}{2}\langle\overline{110}\rangle$ and hard $\{001\} \frac{1}{2}\langle\overline{1} 10\rangle$ slip systems in $\mathrm{MgO}^{[70]}$ highlights the reduced relative importance of plasticity size effects on yielding on slip systems with high intrinsic strength governed by the lattice resistance rather than discrete obstacles and source length. 


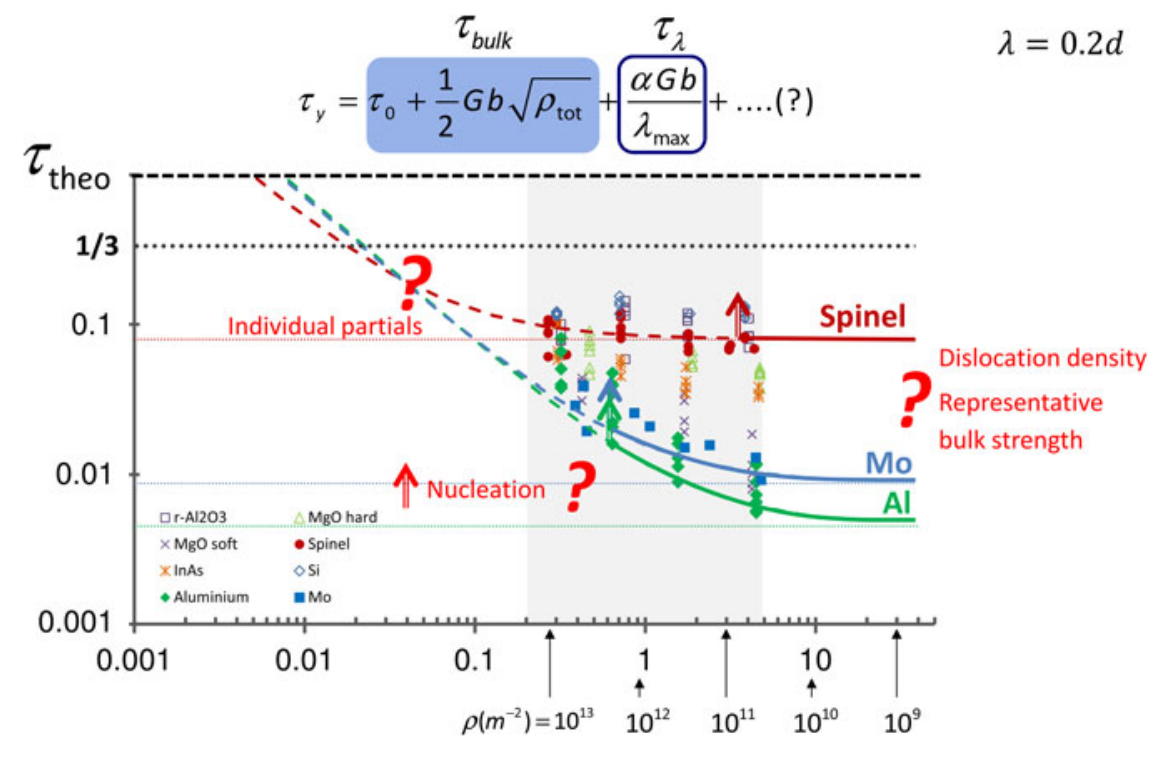

Figure 7. Comparison of the effect of size on critical resolved shear stress across material classes, including FCC Al (unpublished), BCC Mo, ${ }^{[98]}$ the soft $\{110\} \frac{1}{2}\left\langle\overline{110}\right.$, and hard $\{001\} \frac{1}{2}\langle\overline{1} 10\rangle$ slip systems in $\mathrm{MgO},{ }^{[70]}$ the oxide ceramics $\mathrm{MgAl}_{2} \mathrm{O}_{4}$ spinel, and $\mathrm{Al}_{2} \mathrm{O}_{3}$ alumina (unpublished) as well as the semiconductors InAs (unpublished) and $\mathrm{Si}^{[31]}$

dislocation nucleation, ${ }^{[63]}$ a distinction based on variable rate testing also appears difficult. It should be noted, however, that in many cases stable deformation can be achieved even in brittle crystals. Under such conditions, continuous formation of new dislocations is required and where surface steps have been formed as a result of slip crossing the pillar, the nucleation stresses will fall significantly ${ }^{[64]}$ to or below the stresses required for nucleation motion.

An example of the surface affecting scatter and strength of silicon micropillars is shown as part of Fig. 3, where testing of pristine $2 \mu \mathrm{m}$ pillars at room temperature led to appreciable scatter, presumably due to the need to nucleate dislocations from a fairly pristine surface damaged mostly in terms of amorphization during FIB milling, but with no line defects visible by TEM in the undeformed volume. ${ }^{[31]}$ Consistently, testing at the same temperature after exposure to some hightemperature surface oxidation resulted in a much smaller scatter and average strength values toward the lower bound of those measured in the pristine pillars. ${ }^{[31]}$

In general, the effect of size on strength is less pronounced in hard materials, but also more difficult to quantify. This is due to the missing overlap in sample size tested in brittle materials,
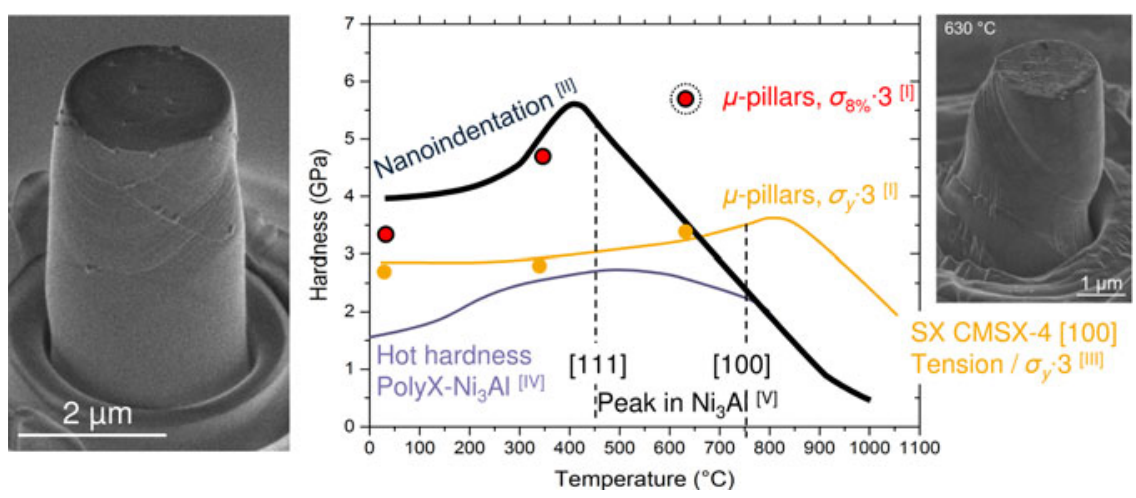

Figure 8. High-temperature microcompression experiments. First demonstrated in air on spine $\left.\right|^{[35]}$ to $400{ }^{\circ} \mathrm{C}$ (left) and in vacuum to $630{ }^{\circ} \mathrm{C}$ on the superalloy CMSX-4 tested ${ }^{[36]}$ (right). Extensive plasticity at $200^{\circ} \mathrm{C}$ in spinel, about $1500^{\circ} \mathrm{C}$ below significant plasticity is commonly achieved in conventional uniaxial testing without hydrostatic pressure, highlights again the effect of size on fracture, while the data obtained on the superalloy reveals the importance of uniaxial testing and choice of representative strain in comparison with macroscopic data and high-temperature nanoindentation affected by the 3D stress-state in the highly anisotropic crystal. Image of spinel micropillar (left) adapted from Ref. 35 and plotted data taken from $[\mathrm{I}],{ }^{[36]}[\mathrm{II}],{ }^{[99]}[\mathrm{III}],{ }^{[11]}[\mathrm{IV}],{ }^{[100]}[\mathrm{V}] .{ }^{[101]} \mathrm{Images}$ reprinted with permission by Elsevier from Ref. 35 and Cambridge University Press from Ref. 36. 
where samples of the order of microns can be deformed plastically, but no bulk samples can be prevented from fracturing at low temperatures. A representative bulk yield stress then needs to be estimated from macroscopic data collected at high temperatures and extrapolated toward lower temperatures. This approach includes significant errors in the application of any type of equation describing thermal activation and the resulting Peierls barrier or lattice resistance at temperatures above $0 \mathrm{~K}$, such as ${ }^{[65,66]}$

$$
\tau\left(T, \rho_{\mathrm{m}}, \dot{\gamma}\right)=\tau_{\mathrm{P}}+\frac{k T}{V} \ln \left(\frac{\dot{\gamma}}{\rho_{\mathrm{m}} b^{2} v_{\mathrm{A}}}\right),
$$

where $\tau_{\mathrm{P}}$ is the Peierls stress (i.e., the lattice resistance at $0 \mathrm{~K}$ ), $k$ the Boltzmann constant, $T$ the absolute temperature, $V$ the activation volume, $\dot{\gamma}$ the shear strain rate, $\rho_{\mathrm{m}}$ the mobile dislocation density, $b$ the Burgers vector, and $v_{\mathrm{A}}$ an attempt frequency of the order of $10^{11} \mathrm{~s}^{-1} \cdot{ }^{65,67]}$ There are several parameters, which are difficult to determine accurately in a small-scale experiment, even if the microsample has been machined from the same bulk material, as the dislocation density may have been changed by FIB milling ${ }^{[68]}$ and be affected by dislocation exhaustion during deformation. ${ }^{[69]}$ In addition, the shear strain rate may vary locally for a tapered pillar. A more detailed discussion of this difficulty may be found in Ref. 70. A direct comparison of different slip systems in the same material, while maintaining a constant level of FIB damage and similar effects of taper, confirms the general trend of an increased size effect at the reduced bulk strength (Fig. 6).

A last difficulty in achieving a direct comparison between bulk and microscale deformation may occur where dislocations move as dissociated partials with an increasing dissociation distance as the stress on the slip plane is raised. ${ }^{[71]}$ Where the sample size is reduced, the leading partial may cross the entire volume without nucleation of the trailing partial, as shown, for example, in GaAs. ${ }^{[26]}$ The implications for the stresses measured must then be assessed carefully in each case. Possible strategies to avoid this problem include careful choice of the crystal orientation such that the Schmid factor becomes larger for the trailing partial and selection of as large a pillar size as possible.

\section{Thermal activation of plasticity}

In case of hard materials, the study of thermal activation is of particular interest for three reasons: firstly, high-temperature mechanical properties are often of interest in those to be applied at high temperatures. Secondly, the underlying deformation mechanisms and their rate-limiting steps may be understood in greater detail by studying the associated activation volumes and therefore rate and temperature dependence [cf. Eq. (1)] and, thirdly, correlation with macroscopic experiments is usually confined to reference data at high temperatures, in which case the interpolated gap should be minimized.

An example of high-temperature microcompression testing is shown in Fig. 8. Having first been demonstrated in air ${ }^{[35]}$ based on the oxide ceramic $\mathrm{MgAl}_{2} \mathrm{O}_{4}$ and a few years later in vacuum $^{[36]}$ initially using a superalloy, it is now routinely available to several hundred degrees and being developed based on similar efforts in nanoindentation to $1000{ }^{\circ} \mathrm{C}$ in order to achieve temperatures relevant to operation in turbines. ${ }^{[72]}$ Especially in the highly anisotropic superalloys, the advantage of uniaxial testing is again apparent in that macroscopic yield stresses are reproduced in uniaxial compression (cf. pillar and macroscopic yield stress in Fig. 8), while in nanoindentation the triaxial stress-state causes significant deviation from uniaxial test results even if the $8 \%$ flow stress is taken as a reference, consistent with the change in superalloy properties based on orientation.

Exemplified above in the case of silicon, high-temperature tests can give valuable information regarding transitions in deformation mechanism, thermal activation and properties in a certain temperature range. However, studies of rate sensitivity at a given temperature as well as creep/relaxation testing at the extremes of slow rates/long times are often of interest, either where not enough measurements can be taken in a specific temperature regime to extract a gradient or where creep mechanisms are of interest. ${ }^{[42,73-76]}$ Strain rate jump tests and creep/ relaxation hold segments may therefore be employed in microcompression in a similar way to macroscopic testing (Fig. 9). Points to consider when performing such experiments usually include the change in cross-sectional area in ex situ experiments, compatibility of tip and sample material at elevated temperatures $^{[77]}$ and long contact times as well as the effect of temperature on gallium, both positive and negative, by encouraging diffusion from the sample surface into the bulk or formation of low-melting phases.

\section{Extracting general principles of plasticity}

Where fundamental deformation mechanisms and the effect of local atomic arrangement and bonding character are of interest, experiments are often correlated with ab initio calculations in order to elucidate the underlying atomic environment. ${ }^{[78,79]}$ However, in crystals with large unit cells and especially where repeating sub-units are also large, the use of ab initio approaches is limited by the size of the required cell. Other modeling approaches, such as atomistic modeling requiring suitable interatomic potentials ${ }^{[80]}$ and novel methods for extraction of dislocation core structure ${ }^{[81]}$ and lattice resistance ${ }^{[9]}$ are advancing continuously. Their application to complex crystals will be of particular interest where not only computation time for ab initio calculations is an issue, but also where there is a direct application of commonly accepted concepts. This applies for example to the use of the generalized stacking fault energy. ${ }^{[82]}$ Usually computed for a few selected planes, these may not be straightforward to interpret, as they do not give dislocation core structures directly and also do not immediately highlight complicated deformation mechanisms relying on coordinated movement on adjacent planes, e.g., synchroshear, ${ }^{[14]}$ or mechanisms based on shuffling of atoms, as 

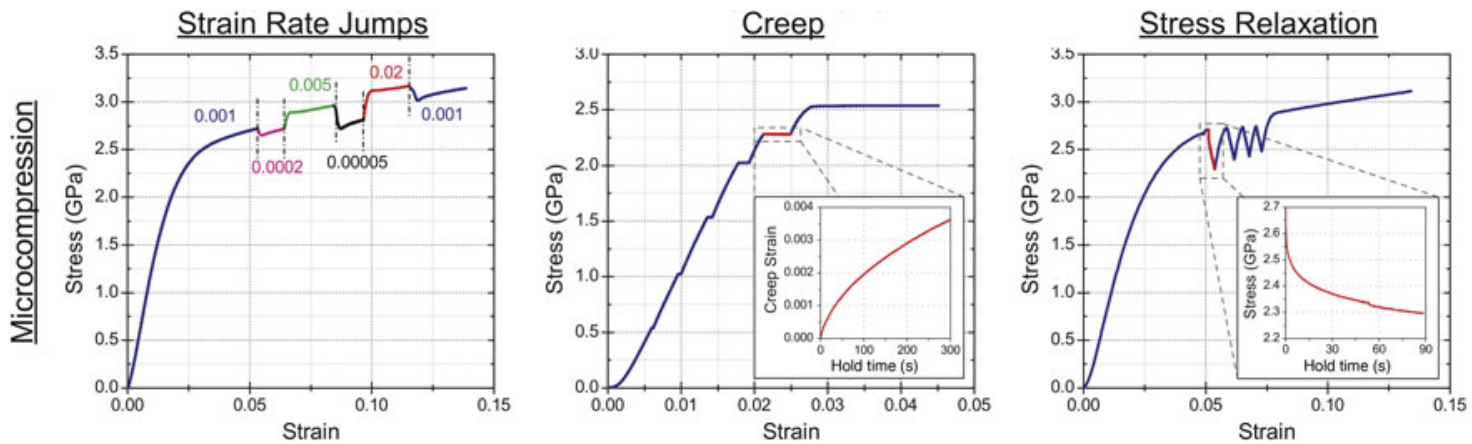

Figure 9. Studies of rate sensitivity in nickel, including rate jump testing, creep, and relaxation hold segments in microcompression inside the SEM. ${ }^{\text {[38] }}$ Reprinted with permission by Elsevier from Ref. 38.

proposed for the giant metadislocation cores of quasicrystal approximants. $^{[83]}$

However, the addition of modeling to the basic approach of nanomechanical testing and simple microstructural characterization is nevertheless powerful, particularly where either the modeling or more in-depth TEM-based methods are individually too time-consuming in execution or subsequent analysis to perform for a vast matrix of crystal orientations, lattice planes, etc. While microcompression can enable the quantitative characterization of activated slip systems in a crystal of unknown slip geometries in combination with TEM, this approach does not directly give defect structures. These are analyzed by time-intensive characterization methods such as two-beam imaging or LACBED analysis of Burgers vectors ${ }^{[84]}$ and HR-TEM of defects to obtain their atomic structure. Guided by initial experimental results - such as operative slip planes from microcompression with EBSD and/or conventional TEM plane trace analysis - $a b$ initio calculations can be focused based on this experimental data. The calculations can, for example, identify slip planes for generalized stacking fault calculations, which in turn guides high-resolution work in identifying potential Burgers vectors and stacking faults, e.g., the choice of membrane orientation. In this way, the combination of both approaches also offers a strategy to find correlations between crystal structure and bonding conditions on the one hand and critical stresses, active slip systems, and defect structures on the other, even in complex crystals where current understanding is very limited. An example of such an approach is summarized in Fig. 10, where the study of plasticity in the hard coating material and superconductor $\mathrm{Mo}_{2} \mathrm{BC}$ has benefited from the closely linked analysis by both ab initio, nanomechanical and electron microscopy methods. ${ }^{[85]}$

\section{Conclusions and future challenges}

Microcompression has the potential to dramatically expand our knowledge of plasticity mechanisms in hard, brittle and anisotropic crystals and extend our understanding of the interplay between crystal structure and defect mobility toward high crystalline complexity.

The major challenge overcome by scaling down the conventional uniaxial compression is the suppression of cracking, making experimental data on plasticity and subsequent analysis of plasticity mechanisms available at low temperatures and in the most brittle materials not previously accessible. In addition,
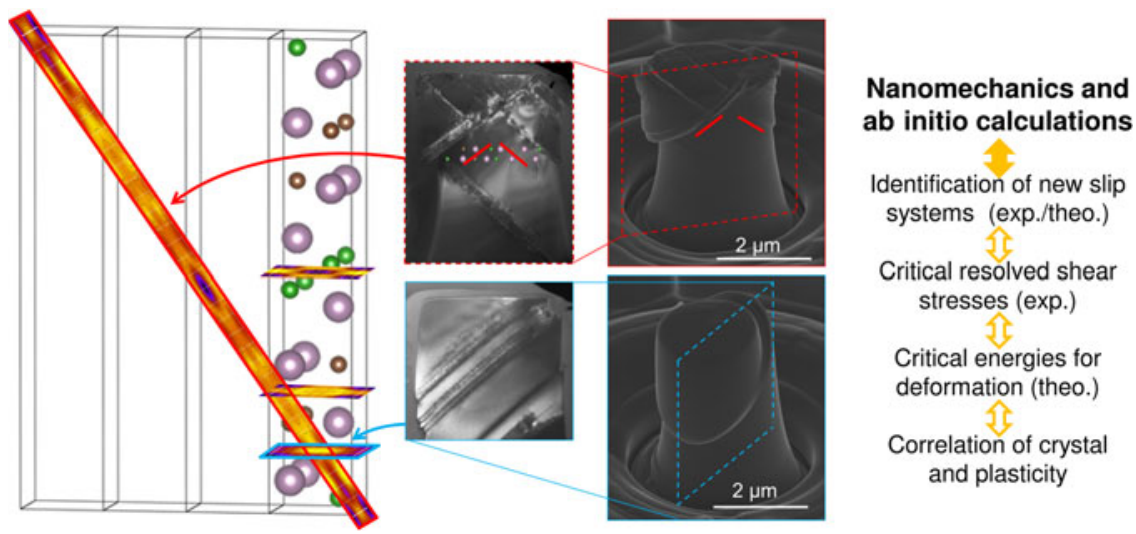

Figure 10. Combination of ab initio calculations and microcompression with SEM/EBSD and TEM. Gamma surface calculated by B. Meyer and T. Klöffel. ${ }^{[85]}$ 
quantitative measurements of stresses in the hardest materials are less affected by size effects.

Challenges in improving both execution and interpretation of studies on hard materials using microcompression will include the:

- Evaluation of the role of dislocation nucleation, its impact on stresses measured and strategies to assure dislocation motion rather than nucleation is the mechanisms governing plasticity in the experiment.

- Study of further size effects on deformation, such as the motion of individual partials. This needs to be considered in greater detail and its effect on critical stresses and residual defect structures resolved for the case of more complex unit cells.

- Implementation of reliable and stable high-temperature testing techniques, including compatible indenter tip materials, suitable sample preparation methods and availability of dedicated equipment, and transparent strategies for data analysis.

- Development of computational methods complementing future studies to elucidate the structure and motion of dislocations in complex crystals.

- Acceleration of test routines, preparation and analysis in order to allow systematic experimental matrices and optimization of analytical depth for each given sub-set of experiments.

- Adaptation and use of novel combinatorial techniques allowing testing at the single-crystal level where limitations exist with respect to established techniques, such as small grain sizes in thin films and diffusion times as well as phase width in diffusion multiples.

Whatever progress will be achieved over the next years, systematic studies of complex crystals varying structure and elemental composition without restrictions on the availability of large single crystals or brittleness have the potential to answer fundamental questions in our understanding of plasticity. They can open our horizon for materials development and search of new candidates for structural materials enabling the future technologies we already envision and the often extreme conditions associated with them.

\section{Acknowledgments}

The author would like to thank Dr. J. S. K.-L. Gibson and the reviewers for their encouragement and constructive criticism on the manuscript.

\section{References}

1. F. Östlund, K. Rzepiejewska-Malyska, K. Leifer, L.M. Hale, Y. Tang, R. Ballarini, W.W. Gerberich, and J. Michler: Brittle-to-ductile transition in uniaxial compression of silicon pillars at room temperature. Adv. Funct. Mater. 19, 2439 (2009).

2. F. Östlund, P.R. Howie, R. Ghisleni, S. Korte, K. Leifer, W.J. Clegg, and J. Michler: Ductile-brittle transition in micropillar compression of GaAs at room temperature. Phil. Mag. 91, 1190 (2011).

3. P. Zongrui, F. Martin, S. Stefanie, N. Roman, S. Bob, R. Dierk, and N. Jörg: Rapid theory-guided prototyping of ductile Mg alloys: from binary to multi-component materials. N. J. Phys. 17, 093009 (2015).
4. D.T. Pierce, J.A. Jiménez, J. Bentley, D. Raabe, and J.E. Wittig: The influence of stacking fault energy on the microstructural and strainhardening evolution of $\mathrm{Fe}-\mathrm{Mn}-\mathrm{Al}-\mathrm{Si}$ steels during tensile deformation. Acta Mater. 100, 178 (2015).

5. A. Koester, A. Ma, and A. Hartmaier: Atomistically informed crystal plasticity model for body-centered cubic iron. Acta Mater. 60, 3894 (2012).

6. C. Marichal, H. Van Swygenhoven, S. Van Petegem, and C. Borca: $\{110\}$ Slip with \{112\} slip traces in bcc Tungsten. Sci. Rep. 3, 2547 (2013).

7. D.M. Marsh: Plastic flow in glass. Proc. R. Soc. A 279, 420 (1963).

8. M.S. Paterson and T-F. Wong: Experimental Rock Deformation: The Brittle Field (Springer, Heidelberg, 2005).

9. P. Cordier, J. Amodeo, and P. Carrez: Modelling the rheology of $\mathrm{MgO}$ under Earth's mantle pressure, temperature and strain rates. Nature 481, 177 (2012).

10. G. Gottstein: Physical Foundations of Materials Science (Springer, Berlin-Heidelberg, 2013).

11. R.C. Reed: The Superalloys_-Fundamentals and Applications (Cambridge University Press, Cambridge, UK, 2006).

12. J-B. le Graverend, J. Cormier, P. Caron, S. Kruch, F. Gallerneau, and J. Mendez: Numerical simulation of $\gamma / \gamma^{\prime}$ microstructural evolutions induced by TCP-phase in the MC2 nickel base single crystal superalloy. Mater. Sci. Eng. A 528, 2620 (2011).

13. P. Carvalho and J.T.M. De Hosson: Stacking faults in the $\mathrm{Co}_{7} \mathrm{~W}_{6}$ isomorph of the $\mu$ phase. Scr. Mater. 45, 333 (2001).

14. M.F. Chisholm, S. Kumar, and P. Hazzledine: Dislocations in complex materials. Science 307, 701 (2005).

15. K. Hiraga, T. Yamamoto, and M. Hirabayashi: Intermetallic compounds of the $\mu$-and $\mathrm{P}$-phases of $\mathrm{C}_{7} \mathrm{Mo}_{6}$ studied by $1 \mathrm{MV}$ electron microscopy. Trans. Jpn. Inst. Met. 24, 421 (1983).

16. H. ur Rehman, K. Durst, S. Neumeier, A.B. Parsa, A. Kostka, G. Eggeler, and M. Göken: Nanoindentation studies of the mechanical properties of the $\mu$ phase in a creep deformed Re containing nickel-based superalloy. Mater. Sci. Eng. A 634, 202 (2015).

17. M.D. Uchic, D.M. Dimiduk, J.N. Florando, and W.D. Nix: Sample dimensions influence strength and crystal plasticity. Science 305, 986 (2004).

18. M. Uchic, P. Shade, and D. Dimiduk: Micro-compression testing of fcc metals: a selected overview of experiments and simulations. JOM 61, 36 (2009).

19. O. Kraft, P.A. Gruber, R. Mönig, and D. Weygand: Plasticity in confined dimensions. Annu. Rev. Mater. Res. 40, 293 (2010).

20. S.S. Brenner: Tensile strength of whiskers. J. Appl. Phys. 27, 1484 (1956).

21. T. Csanadi, M. Bl'anda, A. Duszova, N.Q. Chinh, P. Szommer, and J. Dusza: Deformation characteristics of WC micropillars. J. Eur. Ceram. Soc. 34, 4099 (2014).

22. H. Ghassemi-Armaki, R. Maaß, S.P. Bhat, S. Sriram, J.R. Greer, and K. S. Kumar: Deformation response of ferrite and martensite in a dualphase steel. Acta Mater. 62, 197 (2014).

23. P.R. Howie, S. Korte, and W.J. Clegg: Fracture modes in micropillar compression of brittle crystals. J. Mater. Res. 27, 141 (2012).

24. L. Jiang and N. Chawla: Mechanical properties of $\mathrm{Cu}_{6} \mathrm{Sn}_{5}$ intermetallic by micropillar compression testing. Scr. Mater. 63, 480 (2010).

25. S. Korte, M. Ritter, C. Jiao, P. Midgley, and W. Clegg: Three-dimensional electron backscattered diffraction analysis of deformation in $\mathrm{MgO}$ micropillars. Acta Mater. 59, 7241 (2011).

26. J. Michler, K. Wasmer, S. Meier, F. Ostlund, and K. Leifer: Plastic deformation of gallium arsenide micropillars under uniaxial compression at room temperature. Appl. Phys. Lett. 90, 043123 (2007).

27. B. Moser, K. Wasmer, L. Barbieri, and J. Michler: Strength and fracture of Si micropillars: a new scanning electron microscopy-based microcompression test. J. Mater. Res. 22, 1004 (2007).

28. J. Rabier, A. Montagne, J.M. Wheeler, J.L. Demenet, J. Michler, and R. Ghisleni: Silicon micropillars: high stress plasticity. Phys. Status Solidi A 10, 11 (2013).

29. R. Soler, J.M. Molina-Aldareguia, J. Segurado, J. Llorca, R.I. Merino, and V.M. Orera: Micropillar compression of LiF [100] single crystals: effect of size, ion irradiation and misorientation. Int. J. Plast. 36, 50 (2012). 
30. N. Takata, H. Ghassemi Armaki, Y. Terada, M. Takeyama, and K. S. Kumar: Plastic deformation of the $\mathrm{C}_{14}$ Laves phase $(\mathrm{Fe}, \mathrm{Ni})_{2} \mathrm{Nb}$. Scr. Mater. 68, 615 (2013).

31. S. Korte, J.S. Barnard, R.J. Stearn, and W.J. Clegg: Deformation of silicon-insights from microcompression testing at $25-500^{\circ} \mathrm{C}$. Int. J. Plast. 27, 1853 (2011).

32. S. Kiani, J.M. Yang, and S. Kodambaka: Nanomechanics of refractory transition-metal carbides: a path to discovering plasticity in hard ceramics. J. Am. Ceram. Soc. 98, 2313 (2015).

33. J. Rabier, L. Pizzagalli, J.L. Demenet, J.P. Hirth, and L. Kubin: Chapter 93 dislocations in silicon at high stress. In Dislocations in Solids, edited by J. Hirth and L. Kubin (Elsevier, Amsterdam, 2010), pp. 47.

34. S. Korte and W.J. Clegg: Studying plasticity in hard and Soft Nb-Co intermetallics. Adv. Eng. Mater. 14, 991 (2012).

35. S. Korte and W. Clegg: Micropillar compression of ceramics at elevated temperatures. Scr. Mater. 60, 807 (2009).

36. S. Korte, R.J. Stearn, J.M. Wheeler, and W.J. Clegg: High temperature microcompression and nanoindentation in vacuum. J. Mater. Res. 27, 167 (2012).

37. A. Harris, B. Beake, D. Armstrong, and M. Davies: Development of high temperature nanoindentation methodology and its application in the nanoindentation of polycrystalline tungsten in vacuum to $950^{\circ} \mathrm{C}$. Exp. Mech. (2016) (in press). doi: 10.1007/s11340-016-0209-3.

38. J.M. Wheeler, D.E.J. Armstrong, W. Heinz, and R. Schwaiger: High temperature nanoindentation: the state of the art and future challenges. Curr. Opin. Solid State Mater. Sci. 19, 354 (2015).

39. K. Durst and V. Maier: Dynamic nanoindentation testing for studying thermally activated processes from single to nanocrystalline metals. Curr. Opin. Solid State Mater. Sci. 19, 340 (2015).

40. N.M. Jennett and J. Nunn: High resolution measurement of dynamic (nano) indentation impact energy: a step towards the determination of indentation fracture resistance. Phil. Mag. 91, 1200 (2011).

41. P.S. Phani and W. Oliver: A direct comparison of high temperature nanoindentation creep and uniaxial creep measurements for commercial purity aluminum. Acta Mater. 111, 31 (2016).

42. V. Maier, B. Merle, M. Göken, and K. Durst: An improved long-term nanoindentation creep testing approach for studying the local deformation processes in nanocrystalline metals at room and elevated temperatures. J. Mater. Res. 28, 1177 (2013).

43. S. Korte and W. Clegg: Onset of plasticity in $\ln _{x} G a_{1-x} A$ s multilayers. Acta Mater. 58, 59 (2010).

44. C. Walter, J.M. Wheeler, J.S. Barnard, R. Raghavan, S. Korte-Kerzel, P. Gille, J. Michler, and W.J. Clegg: Anomalous yielding in the complex metallic alloy $\mathrm{Al}_{13} \mathrm{C}_{4}$. Acta Mater. 61, 7189 (2013).

45. S.X. Song, Y.H. Lai, J.C. Huang, and T.G. Nieh: Homogeneous deformation of Au-based metallic glass micropillars in compression at elevated temperatures. Appl. Phys. Lett. 94, 061911 (2009).

46. D. Jang and J.R. Greer: Transition from a strong-yet-brittle to a stronger-and-ductile state by size reduction of metallic glasses. Nat. Mater. 9, 215 (2010).

47. Y. Zou, S. Maiti, W. Steurer, and R. Spolenak: Size-dependent plasticity in an Nb 25 Mo 25 Ta 25 W 25 refractory high-entropy alloy. Acta Mater. 65, 85 (2014)

48. R. Lacroix, V. Chomienne, G. Kermouche, J. Teisseire, E. Barthel, and S. Queste: Micropillar testing of amorphous silica. Int. J. Appl. Glass Sci. 3, 36 (2012).

49. D. Kiener, W. Grosinger, and G. Dehm: On the importance of sample compliance in uniaxial microtesting. Scr. Mater. 60, 148 (2009).

50. D. Kiener, C. Motz, and G. Dehm: Micro-compression testing: a critical discussion of experimental constraints. Mater. Sci. Eng. A 505, 79 (2009).

51. D. Kiener, C. Motz, G. Dehm, and R. Pippan: Overview on established and novel FIB based miniaturized mechanical testing using in-situ SEM. Int. J. Mater. Res. 100, 1074 (2009).

52. D. Kiener, C. Motz, M. Rester, M. Jenko, and G. Dehm: FIB damage of Cu and possible consequences for miniaturized mechanical tests. Mater. Sci. Eng. A 459, 262 (2007).

53. M.D. Uchic, P.A. Shade, and D. Dimiduk: Plasticity of micrometer-scale single crystals in compression. Annu. Rev. Mater. Res. 39, 361 (2009).
54. W. Kang, M. Merrill, and J.M. Wheeler: In situ thermomechanical testing methods for micro/nano-scale materials. Nanoscale 9, 2666 (2017).

55. P.A. Shade, R. Wheeler, Y.S. Choi, M.D. Uchic, D.M. Dimiduk, and H.L. Fraser: A combined experimental and simulation study to examine lateral constraint effects on microcompression of single-slip oriented single crystals. Acta Mater. 57, 4580 (2009).

56. K. Kendall: Impossibility of comminuting small particles by compression. Nature 272, 710 (1978).

57. A.A. Griffith: The phenomena of rupture and flow in solids Trans. R. Soc. Lond. A221, 163 (1920).

58. J.R. Greer and J.T.M. De Hosson: Plasticity in small-sized metallic systems: intrinsic versus extrinsic size effect. Prog. Mater. Sci. 56, 654 (2011).

59. M.W. Barsoum and M. Radovic: Elastic and mechanical properties of the MAX phases. Annu. Rev. Mater. Res. 41, 195 (2011).

60. G. Baptiste, S.S. Andreas, P.F. Carl, and A. Eduard: Strength effects in micropillars of a dispersion strengthened superalloy. Adv. Eng. Mater. 12, 385 (2010).

61. T.A. Parthasarathy, S.I. Rao, D.M. Dimiduk, M.D. Uchic, and D.R. Trinkle: Contribution to size effect of yield strength from the stochastics of dislocation source lengths in finite samples. Scr. Mater. 56, 313 (2007).

62. K.E. Johanns, A. Sedlmayr, P. Sudharshan Phani, R. Mönig, O. Kraft, E.P. George, and G.M. Pharr: In-situ tensile testing of single-crystal molybdenum-alloy fibers with various dislocation densities in a scanning electron microscope. J. Mater. Res. 27, 508 (2012).

63. T. Zhu, J. Li, A. Samanta, A. Leach, and K. Gall: Temperature and Strain-rate dependence of surface dislocation nucleation. Phys. Rev. Lett. 100, 025502 (2008).

64. C. Li and G. Xu: Critical conditions for dislocation nucleation at surface steps. Phil. Mag. 86, 2957 (2006).

65. V. Bhakhri, J. Wang, N. Ur-rehman, C. Ciurea, F. Giuliani, and L. J. Vandeperre: Instrumented nanoindentation investigation into the mechanical behavior of ceramics at moderately elevated temperatures. J. Mater. Res. 27, 65 (2012).

66. W.J. Clegg, L.J. Vandeperre, and J.E. Pitchford: Energy changes and the lattice resistance. Key Eng. Mater. 317-318, 271 (2006).

67. H.J. Frost and M.F. Ashby: Deformation-Mechanism Maps, the Plasticity and Creep of Metals and Ceramics (Elsevier, Amsterdam, 1982).

68. S. Shim, H. Bei, M.K. Miller, G.M. Pharr, and E.P. George: Effects of focused ion beam milling on the compressive behaviour of directionally solidified micropillars and the nanoindentation response of an electropolished surface. Acta Mater. 57, 503 (2009).

69. D. Kiener and A.M. Minor: Source truncation and exhaustion: insights from quantitative in situ TEM tensile testing. Nano Lett. 11, 3816 (2011).

70. S. Korte and W. Clegg: Discussion of the dependence of the effect of size on the yield stress in hard materials studied by microcompression of Mg0. Phil. Mag. 91, 1150 (2011).

71. K. Wessel and $\mathrm{H}$. Alexander: On the mobility of partial dislocations in silicon. Phil. Mag. 35, 1523 (1977).

72. B.D. Beake, A.L. Harris, G. Fox-Rabinovich, G. Rauh, M.I. Davies, $D$. Armstrong, and V. Vishnyakov: Nanomechanical testing of thin films to $950^{\circ} \mathrm{C}$. In 15th International Conference on Plasma Surface Engineering PSE 2016, Garmisch-Partenkirchen, Germany, 2016.

73. J. Wehrs, M.J. Deckarm, J.M. Wheeler, X. Maeder, R. Birringer, S. Mischler, and J. Michler: Elevated temperature, micro-compression transient plasticity tests on nanocrystalline Palladium-Gold: probing activation parameters at the lower limit of crystallinity. Acta Mater. 129, $124(2017)$

74. J. Wheeler, V. Maier, K. Durst, M. Göken, and J. Michler: Activation parameters for deformation of ultrafine-grained aluminium as determined by indentation strain rate jumps at elevated temperature. Mater. Sci. Eng. A. 585, 108 (2013).

75. J. Wheeler, L. Thilly, A. Morel, A. Taylor, A. Montagne, R. Ghisleni, and J. Michler: The plasticity of indium antimonide: Insights from variable temperature, strain rate jump micro-compression testing. Acta Mater. 106, 283 (2016).

76. V. Maier, K. Durst, J. Mueller, B. Backes, H.W. Höppel, and M. Göken: Nanoindentation strain-rate jump tests for determining the local strain- 
rate sensitivity in nanocrystalline $\mathrm{Ni}$ and ultrafine-grained Al. J. Mater. Res. 26, 1421 (2011).

77. J. Wheeler and J. Michler: Invited article: indenter materials for high temperature nanoindentation. Rev. Sci. Instrum. 84, 101301 (2013).

78. K. Gouriet, P. Carrez, P. Cordier, A. Guitton, A. Joulain, L. Thilly, and C. Tromas: Dislocation modelling in $\mathrm{Ti}_{2} \mathrm{AIN}$ MAX phase based on the Peierls-Nabarro model. Phil. Mag. 95, 2539 (2015).

79. J. Emmerlich, D. Music, M. Braun, P. Fayek, F. Munnik, and J.M. Schneider: A proposal for an unusually stiff and moderately ductile hard coating material: $\mathrm{Mo}_{2} \mathrm{BC}$. J. Phys. D: Appl. Phys. 42, 185406 (2009).

80. T. Hammerschmidt, R. Drautz, and D.G. Pettifor: Atomistic modelling of materials with bond-order potentials. Int. J. Mater. Res. 100, 1479 (2009).

81. A.M. Walker, J.D. Gale, B. Slater, and K. Wright: Atomic scale modelling of the cores of dislocations in complex materials part 2: applications. Phys. Chem. Chem. Phys. 7, 3235 (2005)

82. V. Vítek: Intrinsic stacking faults in body-centred cubic crystals. Phil. Mag. 18, 773 (1968).

83. M. Heggen and M. Feuerbacher: Core structure and motion of metadislocations in the orthorhombic structurally complex alloy $\mathrm{Al}_{13} \mathrm{Co}_{4}$. Mat. Res. Lett. 2, 146 (2014)

84. J-P. Morniroli: Large-angle Convergent-beam Electron Diffraction Applications to Crystal Defects (French Society of Microscopies, Paris, 2004).

85. S. Korte-Kerzel, T. Klöffel, and B. Meyer: Plasticity of an atomically layered crystal: a combined nanomechanical and ab initio study on $\mathrm{Mo}_{2} \mathrm{BC}$. Under review (2017).

86. M. Simonetti and P. Caron: Role and behaviour of $\mu$ phase during deformation of a nickel-based single crystal superalloy. Mater. Sci. Eng. A 254, 1 (1998).

87. T. Csanadi, P. Szommer, N.Q. Chinh, S. Grasso, J. Dusza, and M. Reece: Plasticity in $\mathrm{ZrB}_{2}$ micropillars induced by anomalous slip activation. $J$. Eur. Ceram. Soc. 36, 389 (2016).

88. D. Janda, H. Ghassemi-Armaki, E. Bruder, M. Hockauf, M. Heilmaier, and K.S. Kumar: Effect of strain-rate on the deformation response of D03-ordered $\mathrm{Fe}_{3} \mathrm{Al}$. Acta Mater. 103, 909 (2016).

89. Z. Chen, N.L. Okamoto, M. Demura, and H. Inui: Micropillar compression deformation of single crystals of $\mathrm{CO}_{3}(\mathrm{Al}, \mathrm{W})$ with the $\mathrm{L} 1(2)$ structure. Scr. Mater. 121, 28 (2016).

90. J.M. Wheeler, L. Thilly, A. Morel, A.A. Taylor, A. Montagne, R. Ghisleni, and J. Michler: The plasticity of indium antimonide: insights from variable temperature, strain rate jump micro-compression testing. Acta Mater. 106, 283 (2016).

91. J.J. Guo, K.M. Reddy, A. Hirata, T. Fujita, G.A. Gazonas, J.W. McCauley, and M.W. Chen: Sample size induced brittle-to-ductile transition of single-crystal aluminum nitride. Acta Mater. 88, 252 (2015).

92. J.M. Wheeler, C. Niederberger, C. Tessarek, S. Christiansen, and J. Michler: Extraction of plasticity parameters of $\mathrm{GaN}$ with high temperature, in situ micro-compression. Int. J. Plast. 40, 140 (2013).

93. X.M. Zeng, A. Lai, C.L. Gan, and C.A. Schuh: Crystal orientation dependence of the stress-induced martensitic transformation in zirconia-based shape memory ceramics. Acta Mater. 116, 124 (2016).

94. R. Soler, J.M. Molina-Aldareguia, J. Segurado, J. Llorca, R.I. Merino, and V.M. Orera: Micropillar compression of LiF 111 single crystals: effect of size, ion irradiation and misorientation. Int. J. Plast. 36, 50 (2012).

95. S.S. Singh, E.Y. Guo, H.X. Xie, and N. Chawla: Mechanical properties of intermetallic inclusions in Al 7075 alloys by micropillar compression. Intermetallics. 62, 69 (2015).

96. N.L. Okamoto, M. Inomoto, H. Adachi, H. Takebayashi, and H. Inui: Micropillar compression deformation of single crystals of the intermetallic compound zeta-FeZn $\mathrm{n}_{13}$. Acta Mater. 65, 229 (2014).

97. Prof. A.H. Cottrell's lectures. Met. Sci. Heat Treat. 3, 219 (1961).

98. A. Schneider, C. Frick, E. Arzt, W. Clegg, and S. Korte: Influence of test temperature on the size effect in molybdenum small-scale compression pillars. Phil. Mag. Lett. 93, 331 (2013).

99. J. Gibson, S. Schröders, C. Zehnder, and S. Korte-Kerzel: Towards application temperatures-Nanoindentation of CMSX-4 and an Amdry bondcoat to $1000^{\circ} \mathrm{C}$. Under review (2017).
100.D-M. Wee and T. Suzuki: The temperature dependence of hardness of $\mathrm{LI}$ 2 ordered alloys. Trans. Jpn. Inst. Met. 20, 634 (1979).

101.E. Conforto, G. Molénat, and D. Caillard: Comparison of Ni-based alloys with extreme values of antiphase boundary energies: dislocation mechanisms and mechanical properties. Phil. Mag. 85, 117 (2005). 